\title{
A AMPLIAÇÃO DO TELETRABALHO E HOME OFFICE EM TEMPOS DE PANDEMIA E SEUS REFLEXOS NA SAÚDE DO TRABALHADOR
}

Marcela Pereira Ferreira*

Resumo: O desenvolvimento emergente das tecnologias de comunicação em rede possibilitou o implemento de trabalhos realizados de forma remota, fora das dependências do empregador. A pandemia impulsionou ainda mais o fenômeno, tendo em vista a crise sanitária vivenciada em todas as partes do mundo, que impôs medidas restritivas como o isolamento social. Com isso, os postos de trabalho e a produção foram mantidos, evitando o contato físico entre os trabalhadores e a consequente propagação do vírus, de grande caráter letal, causando inúmeros danos físicos e psicológicos na saúde de toda cadeia produtiva e consumidora, que devem ser evitados.

Palavras-chave: Teletrabalho. Home-office. Ampliação. Pandemia. Saúde.

\section{THE EXTENSION OF TELEWORKING AND HOME OFFICE IN PANDEMIC TIMES AND ITS REFLECTIONS ON WORKER HEALTH}

\begin{abstract}
The emerging development of networked communication technologies made it possible to implement work carried out remotely, outside the employer's premises. The pandemic boosted the phenomenon even more, in view of the health crisis experienced in all parts of the world, which imposed restrictive measures such as social isolation. As a result, jobs and production were kept, avoiding physical contact between workers and the consequent spread of the virus, which is highly lethal, causing innumerable physical and psychological damage to the health of the entire production and consumer chain, which must be avoided.
\end{abstract}

Keywords: Teleworking. Home Office. Increase. Pandemic. Health.

\section{INTRODUÇÃO}

A pandemia causada pelo Coronavírus alastrou-se rapidamente por todas as partes do globo, tendo em vista seu alto índice de contágio, bem como desconhecimento acerca do comportamento e mutação do novo vírus, tomando proporções mundiais, deixando uma enorme quantidade de mortos e feridos, sendo que os números aumentam consideravelmente a

\footnotetext{
* Mestranda em Proteção dos Direitos e Garantias Fundamentais pela Universidade de Itaúna/MG. PósGraduanda em Direito Trabalhista e Previdenciário pela UniAmérica. Pós-Graduanda em Direito Público pela Universidade de Franca - UniFran. Graduada em Direito pelo Centro Universitário de Formiga. Advogada $\mathrm{OAB} / \mathrm{MG} \mathrm{n}^{\circ} 207.032$.
} 
cada dia. Com isso, medidas preventivas começaram a ser tomadas, como o uso de máscaras, a higienização das mãos, uso de álcool em gel, e, principalmente, o isolamento social, como forma de evitar o contato direto com o vírus.

O isolamento social, contudo, ocasionou impacto na vida de milhões de pessoas que precisam se locomover diariamente a fim de realizarem seu trabalho e atividades básicas do cotidiano, como a compra de alimentos, medicamentos necessários, pagamento de contas e dívidas, dentre diversas outras atribuições. O mercado de trabalho sofreu diretamente os impactos do isolamento social, com o fechamento de lojas e comércios, funcionando apenas aqueles serviços considerados como "essenciais".

Em tempos de pandemia, é necessário que todas as medidas sejam tomadas a fim de que o vírus seja combatido, bem como que as pessoas não se contagiem, porém, também se faz necessário a adoção de medidas a fim de que os trabalhadores e a comunidade de modo geral não adoeça por outros tipos de doenças, devendo haver medidas com a finalidade de prevenir a saúde física e mental da população diante da crise sanitária, com ações positivas dos governos e demais órgãos públicos.

O avanço tecnológico faz com que parte da empresa migre diretamente para dentro das residências dos empregados, com todas suas funcionalidades, atividades, tarefas, metas e obrigações, de modo que os conceitos jurídicos tradicionais da esfera trabalhista são colocados em dúvida, como a jornada de trabalho, a subordinação direta ao empregador e os horários de repouso, descanso e lazer dos empregados.

Tendo em vista a nova realidade imposta à todos, houve a necessidade de adaptar diversos setores, principalmente no que diz respeito ao trabalho, passando os profissionais a trabalharem muitas vezes em suas próprias residências, naquelas modalidades que são denominadas de teletrabalho ou home office, crescendo de forma significativa o número de trabalhos remotos realizados durante a pandemia, em detrimento do trabalho presencial, que já não pode ser exercido em diversas partes do mundo, tendo em vista a ocorrência de lockdown, toque de recolher, e consequente fechamento da maioria dos comércios e empresas.

Com isso, o artigo analisará a ampliação do trabalho remoto em tempos de pandemia, com análise de conceitos, características, objetivos e regulamentação legal dos institutos do teletrabalho e home office, as principais semelhanças e diferenças existentes entre ambos, legislação normativa e jurisprudencial aplicável acerca do tema, bem como os impactos 
causados na saúde dos trabalhadores devido à nova realidade social e a crise sanitária, com as consequentes mudanças na forma de realização do trabalho.

\section{BREVES CONSIDERAÇÕES E CONCEITO DE TELETRABALHO E HOME OFFICE: PRINCIPAIS DIFERENÇAS E SEMELHANÇAS ENTRE OS INSTITUTOS}

O fenômeno do direito comunitário e das integrações regionais, com a consequente formações de blocos e organismos supranacionais, impulsionaram o fenômeno da globalização, com a aproximação de culturas através dos avanços tecnológicos e aparelhos de alta geração, havendo a conexão instantânea de pessoas em várias partes diferentes do mundo no mesmo momento através da rede mundial de computadores.

Com isso, os trabalhos desenvolvidos em casa ganharam maior destaque, tendo em vista que, ao contrário de antigamente, não é necessário que o empregado esteja nas dependências físicas da empresa para que consiga realizar seu serviço, ao passo que cada vez mais conta com equipamentos tecnológicos e de comunicação em massa, podendo seu trabalho ser realizado, portanto, de igual modo, de sua própria residência ou de qualquer outro lugar em que o empregado se encontre.

Na maioria das vezes, o termo teletrabalho e home office são confundidos, tendo em vista que a maior parte das pessoas acreditam tratar-se de sinônimos. Ocorre que os termos são diferentes e refletem dois institutos jurídicos distintos, cada um com suas peculiaridades e normatividade própria. Os trabalhos remotos passaram a ser adotados em larga escala em razão da pandemia que assolou todas as partes do mundo, sendo uma alternativa para a continuidade do trabalho em tempos de isolamento social.

É de suma importância a diferenciação dos institutos tanto por parte da empresa, devendo estar ciente de qual meio adotar e sua regulamentação, bem como aos empregados, que devem saber seus direitos e deveres, assim como a diferença é importante aos operadores e estudiosos do direito, que cada dia mais torna-se tecnológico e digital, com o implemento de inteligências artificiais e avançadas técnicas eletrônicas, bem como por parte da população em geral, tendo em vista o atual mundo globalizado e digital.

A expressão teletrabalho é utilizada para se referir a todo trabalho que é exercido fora das dependências da empresa. Ou seja, o teletrabalho não pode ser realizado em local que 
tenha alguma relação ou vínculo com o empregador ou o escritório da empresa. Uma das principais características do teletrabalho é que o trabalhador não está sujeito ao controle de sua jornada de trabalho, não recebendo, por tal motivo, adicional de hora extra.

O teletrabalho é uma tendência moderna, implementado e regulamentado legalmente pela Reforma Trabalhista no ano de 2017, ganhando ainda mais força com o cenário pandêmico vivenciado no país, tendo em vista que possibilitou a continuidade do trabalho de modo remoto, sendo uma alternativa que contribuiu para a manutenção dos postos de trabalho e evitou dispensas em massa devido à crise sanitária enfrentada, que refletiu diretamente no mercado econômico, nas linhas de produção e na consumação de mercadorias e bens duráveis e não duráveis.

Um dos maiores benefícios do teletrabalho é o fato do mesmo ser flexível, atemporal, não havendo o controle de jornada, não sendo o pagamento realizado sobre as horas trabalhadas e metas a serem cumpridas. Com isso, existe a possibilidade do trabalhador conciliar atividades cotidianas como exercícios físicos, lazer, estudos, encaixando a realização do trabalho de acordo com seu cronograma diário previamente estabelecido.

A natureza jurídica do teletrabalho é ponto discutido, tendo em vista que o fato de não ser submetido ao controle de jornada, faz com que muitos doutrinadores entendam que não exista a possibilidade de subordinação. Porém, o entendimento majoritário é que o teletrabalhador pode sim ser subordinado à empresas e empregadores, conforme o entendimento de Barbosa (2006, p. 618) acerca do assunto:

\begin{abstract}
Alguns doutrinadores entendem que existe vínculo empregatício no teletrabalho e outros que é uma atividade autônoma. Tudo vai depender do conteúdo da prestação do serviço. Se a empresa tem o controle da atividade realizada pelo teletrabalhador, temos o trabalho subordinado; do contrário se o trabalho é realizado com autonomia, tendo apenas o teletrabalhador recebido as regras antes do início de sua atividade e sem o controle da empresa nas diversas fases de realização do trabalho, então o trabalho é autônomo.
\end{abstract}

Acerca do assunto, existem jurisprudências do Tribunal Superior do Trabalho com o intuito de uniformizar o entendimento sobre o tema. Neste sentido é o entendimento do Ministro Relator Maurício Godinho Delgado no julgamento exposto à seguir:

Isso não elimina, porém, necessariamente, a presença de subordinação na correspondente relação socioeconômica e jurídica entre o trabalhador e seu tomador de serviços, desde que ultrapassado o conceito tradicional desse elemento integrante 
da relação empregatícia em favor de sua dimensão objetiva ou, até mesmo, em favor do conceito de subordinação estrutural. Dentro deste novo, moderno e atualizado enfoque da subordinação, os trabalhadores em domicílio, mesmo enquadrando-se no parâmetro do home office, podem, sim, ser tidos como subordinados e, desse modo, efetivos empregados. (TST. AIRR - 62141-19.2003.5.10.0011. Data de Julgamento: 07/04/2010, Relator Ministro: Mauricio Godinho Delgado, 6 ${ }^{\mathbf{a}}$ Turma, Data de Publicação: DEJT 16/04/2010).

Ocorre que as normas estabelecidas acerca do controle das jornadas de trabalho, tanto em diploma constitucional como em legislação jurídico-normativa, possuem o objetivo de resguardar a saúde e segurança dos trabalhadores, a fim de que os mesmos não sejam submetidos a jornadas longas e exaustivas de trabalho que são prejudiciais à sua saúde em diversos aspectos, como físico, econômico, social e cultural.

Portanto, o não estabelecimento de limites de jornadas de trabalho definidos e estabelecidos previamente podem ser considerados um retrocesso social, tendo em vista a luta pela conquista de direitos trabalhistas assecuratórios de melhores condições ao meio ambiente de trabalho e sua realização, bem como o não controle de jornada pode ser um fator determinante para o adoecimento dos trabalhadores.

Por outro lado, o trabalho home office é considerado aquele trabalho feito em casa, conforme sua tradução literal para a língua portuguesa. Porém, o trabalho home office não precisa ser realizado necessariamente na residência do empregado, mas sim pode ser feito em qualquer outro lugar, desde que seja executado de modo totalmente remoto.

Pode ser que o trabalhador em regime home office conte com um local físico na empresa em caso de eventual necessidade, como imprevistos em sua residência, queda da internet, não funcionamento de meios eletrônicos necessários para o trabalho, dentre outros, que afetam diretamente a realização de seu trabalho habitual.

Não é preciso que o home office seja especificado no contrato de trabalho, diferentemente do teletrabalho, tendo em vista que trata-se apenas de política interna da própria empresa, havendo, contudo, a necessidade do controle de jornada por parte dos empregadores, devendo o empregado realizar a mesma jornada à qual realizaria nas dependências da empresa, nos mesmos horários e intervalos estabelecidos.

O home office, embora seja considerado uma modalidade de trabalho remota, é regido pelas mesmas leis estabelecidas na Consolidação das Leis do Trabalho para o trabalho presencial, cabendo ao empregador escolher a melhor forma de exercer a fiscalização em relação a jornada de trabalho dos empregados, sendo devido aos trabalhadores, por 
consequência direta do controle de jornada, os adicionais de horas extras, adicional noturno, intervalos intrajornadas, dentre outros direitos e benefícios.

Portanto, no regime de trabalho home office é como se o trabalhador exercesse suas funções presencialmente na sede da empresa, porém estará realizando-as de sua residência, possuindo as mesmas regras, forma de pagamento e controle de jornada da mesma maneira como se estivesse trabalhando presencialmente, devendo o empregador fornecer os materiais adequados a fim de que o empregado consiga realizar seu trabalho habitual de sua residência ou de qualquer outro lugar em que se encontre de forma remota.

Ressalta-se que para os empregadores e empresas, na maioria das vezes, existe um enorme benefício na manutenção dos postos de trabalho remotos nas residências dos empregados, tendo em vista que reduzem drasticamente os custos com despesas básicas como energia, instalações e equipamentos físicos para a realização do trabalho, bem com sua manutenção periódica e encargos previstos na legislação trabalhista, como o fornecimento de vale-transporte, alimentação e pagamento de horas extraordinárias aos empregados.

\section{LEGISLAÇÃO ACERCA DAS MODALIDADES DE TRABALHO REMOTAS}

Em decorrência da nova ordem social implantada em todas as partes do mundo devido ao surgimento da pandemia, Martinez e Possídio (2020, p. 25) ressaltam que a legislação trabalhista existente é insuficiente para regulamentar todas as mudanças observadas no cenário nacional, devendo se adequar e estruturar para tanto:

\footnotetext{
As regras celetistas serão insuficientes para resolver os dilemas que surgirão em razão da nova ordem instalada. O contexto é diferente de tudo o que se concebeu para a edição daquelas regras. O momento atual assemelha-se a um dos filmes de ficção científica norteamericanos, aos quais se assiste com incredulidade e até certa admiração com a capacidade inventiva de seus criadores. Os dispositivos celetistas servirão, por óbvio, para esse primeiro momento de caos e mesmo assim, com suas regras afrouxadas, capazes, dessa forma, de serem lançadas sobre os fatos sociais com adequação e razoabilidade, como compete aos operadores do direito fazer, como intérpretes das normas que são, somente a partir do que se terá a efetiva subsunção do fato à regra.
}

São necessários instrumentos efetivos de controle ao coronavírus e, no mesmo sentido, normas trabalhistas capazes de equilibrar o mercado de trabalho, evitando-se demissões e desemprego em massa, devido à influência direta da pandemia na cadeia produtora e 
consumidora, com soluções práticas e necessárias para que os postos de trabalho sejam mantidos, como a utilização de instrumentos de negociação, a concessão de férias coletivas aos funcionários e a migração do trabalho presencial para o trabalho desenvolvido de forma remota.

O teletrabalho encontra-se disciplinado no Capítulo II-A da Consolidação das Leis Trabalhistas, que regulamenta e disciplina seu funcionamento, bem como suas especificidades e regras necessárias para a devida configuração. O artigo 75-B do referido diploma legal dispõe de modo preciso acerca do conceito de teletrabalho, conforme pode ser observado a partir da leitura e análise do dispositivo normativo:

Art. 75-B. Considera-se teletrabalho a prestação de serviços preponderantemente fora das dependências do empregador, com a utilização de tecnologias de informação e de comunicação que, por sua natureza, não se constituam como trabalho externo.

Parágrafo único. O comparecimento às dependências do empregador para a realização de atividades específicas que exijam a presença do empregado no estabelecimento não descaracteriza o regime de teletrabalho. (BRASIL, 1943, Art. 75-B)

É necessário que o contrato individual de trabalho conste expressamente que a prestação de serviços irá ocorrer na modalidade de teletrabalho, devendo ser também especificadas todas as atividades que deverão ser realizadas pelo trabalhador no presente regime laboral. Por meio de simples aditivo contratual pode ocorrer a mudança do regime presencial para o regime de teletrabalho, desde que as duas partes estejam de acordo, o que acontece em larga escala durante a crise sanitária enfrentada no país.

Por outro lado, para que o trabalhador deixe a condição do teletrabalho, passando ao regime presencial, quando há determinação por parte do empregador, além de haver o registro em aditivo contratual correspondente, também se faz necessário a garantia do período mínimo de quinze dias de transição entre os dois regimes.

O contrato escrito deverá estabelecer e constar todas as disposições que dizem respeito ao fornecimento, manutenção e responsabilidade pela aquisição da infraestrutura utilizada para a realização do teletrabalho, bem como acerca dos equipamentos tecnológicos essenciais para a prestação do trabalho remoto, devendo constar também de forma escrita eventual reembolso de despesas arcadas pelo empregado para se adaptar ao período de trabalho em 
casa. Ressalta-se que as utilidades necessárias para a realização do trabalho remoto não vão integrar a remuneração percebida pelo empregado.

O empregador, nesta feita, possui a responsabilidade de instruir devidamente os empregados a respeito de precauções e adequações levadas em conta no período em que o trabalho será realizado de forma remota, fora das dependências do empregador, bem como instruções de como evitar acidentes de trabalho e doenças ocupacionais, devendo o empregado, ciente das recomendações passadas, assinar o correspondente termo de compromisso, a fim de seguir e cumprir corretamente todas as orientações por ele recebidas.

Em relação ao tema da instrução remota passada pelo empregador aos empregados e subordinados no âmbito dos regimes de trabalho à distância, dispõe Homero Batista Mateus da Silva (2017, p. 56) no seguinte sentido:

O art. 75-E, utilizando linguagem patriarcal, já superada no âmbito da saúde e
segurança do trabalho, determina que o empregador instrua os empregados "de
maneira expressa e ostensiva", quanto às precauções para evitar doenças e acidentes,
ao passo que o empregado deve se comprometer a seguir todas as instruções; a tese
de que todos os acidentes tivessem como causa "ato inseguro" do empregado está
superada faz muitos anos, impondo-se análise multifatorial para a compreensão dos
acidentes e doenças a ele equiparadas; por exemplo, em caso de sobrecarga muscular
pelo trabalho de digitação em domicílio - antigamente denominada tendinite - não é
crível que se pense apenas em analisar o descuido do empregado quanto à postura;
elementos relevantes como prazos para entrega dos trabalhos, nível de
complexidade, ritmo exigido, número de toques necessários para dar cobro à
demanda, forma de remuneração, metas impostas e vários outros assuntos correlatos
deverão ser levados em consideração.

Dessa forma, o fato do teletrabalho não possuir controle de jornada externo, conforme estabelecido pela reforma trabalhista, é questionável, tendo em vista que a Constituição Federal assegura a proteção à duração do trabalho como forma de resguardar a proteção à saúde e segurança do trabalhador, não devendo ser diferente com os trabalhadores em regime de teletrabalho, que podem exceder, assim, o número máximo de horas permitidas diariamente sem fazer jus ao pagamento do adicional relacionado às mesmas.

Por sua vez, a modalidade de trabalho home office não encontra abrangência legal expressa, ou seja, não está regulamentado por Lei no ordenamento jurídico brasileiro, ao contrário do observado com o teletrabalho. A Consolidação das Leis do Trabalho não define ou conceitua home office. Contudo, o artigo $6^{\circ}$ da Consolidação das Leis do Trabalho foi alterado através da Lei $n^{\circ}$ 12.551/11, passando a conter a seguinte redação: 
Art. 6. Não se distingue entre o trabalho realizado no estabelecimento do empregador, o executado no domicílio do empregado e o realizado a distância, desde que estejam caracterizados os pressupostos da relação de emprego.

Parágrafo único. Os meios telemáticos e informatizados de comando, controle e supervisão se equiparam, para fins de subordinação jurídica, aos meios pessoais e diretos de comando, controle e supervisão do trabalho alheio. (BRASIL, 1943, Art. 6)

Neste sentido, as modalidades de trabalho remotas são expressamente equiparadas às jornadas de trabalho presencial, possuindo os trabalhadores que atuam em regime de home office ou teletrabalho os mesmos direitos garantidos aos trabalhadores que prestam serviços presencialmente, bem como também possuem os mesmos deveres estabelecidos aos mesmos.

Infere-se, portanto, que aos trabalhadores remotos são garantidos direitos básicos trabalhistas inerentes à todos, como décimo terceiro salário, férias acrescidas de um terço constitucional, FGTS, aplicação de vantagens estabelecidas em diplomas coletivos, dentre diversos outros direitos e benefícios garantidos pela legislação trabalhista pátria, assim como em diplomas constitucionais e demais legislação extravagante vigente no ordenamento jurídico brasileiro que disciplina à respeito do tema.

O artigo 62 da Consolidação das Leis Trabalhistas, por sua vez, expressamente ressalta que aqueles trabalhadores que encontram-se em regime de teletrabalho não possuem controle de jornada, sendo a consequência legal imediata decorrente de tal norma a não percepção do adicional de horas extras, não possuindo os trabalhadores direito ao recebimento da referida gratificação, tendo em vista que sua jornada de trabalho não é controlada externamente pelos empregadores e empresas às quais o empregado é vinculado.

A Medida Provisória 927 do ano de 2020 foi editada com o intuito de disciplinar acerca de medidas trabalhistas emergenciais para o enfrentamento e regulamentação do estado de calamidade pública vivenciado em decorrência da pandemia instaurada no país e seus consequentes reflexos na esfera trabalhista, em especial disciplinando regras mais flexíveis para a implementação e funcionamento do teletrabalho em tempos de crise.

Ocorre que, como não houve consenso sobre a Medida Provisória 927/2020 no Senado, a mesma perdeu sua validade em julho de 2020, sendo que com a caducidade da medida as regras relacionadas ao teletrabalho voltam a ser regulamentadas pelas normas acerca do assunto contidas na Consolidação das Leis do Trabalho, necessitando, por exemplo, de concordância expressa por parte do empregado para ocorrer a alteração entre o regime de trabalho presencial para o telepresencial. 


\section{DIREITO SOCIAL À SAÚDE DO TRABALHADOR}

A saúde é considerada o estado de bem-estar físico, social e mental que o homem possui com seu exterior e interior, ou seja, para consigo mesmo e com tudo aquilo que encontra-se ao seu redor. Saúde é caracterizada como a boa disposição física, mental e psíquica, sendo que uma pessoa é considerada saudável quando seu organismo e funções estruturais e vitais básicas do corpo humano estão em perfeito funcionamento, agindo dentro do ciclo da normalidade e em condições regulares de acordo com os parâmetros medicinais.

Na maior parte dos seguimentos que compõem a sociedade civil contemporânea podese encontrar alguma relação com o direito à saúde, de forma direta ou indireta, tendo em vista que o mesmo acompanha as pessoas em todos os lugares e em todas as atividades cotidianas, em especial na realização de seu trabalho. Para que o trabalho seja realizado de maneira adequada, produtiva e segura para o trabalhador, é necessário que as condições de saúde estejam dentro das normas legais e médicas exigidas para tanto.

A saúde do trabalhador possui diversos pilares, dentre eles a busca por condições de trabalho mais humanizadas, a valorização da saúde da classe operária, a prevenção coletiva no ambiente de trabalho, a implementação de políticas sanitárias e preventivas no trabalho, a participação dos órgãos sindicais como garantidores do direito à saúde e a busca de uma relação saudável entre o binômio trabalho e doenças ocupacionais.

Explica José Antônio Ribeiro de Oliveira Silva (2013, p. 79) que:

Há que se considerar que a proteção à saúde dos trabalhadores, como qualquer
direito fundamental, envolve dois aspectos, um negativo e outro positivo, o primeiro
relacionado a abstenções tanto do Estado quanto do empregador, e o segundo
aglutinando inúmeras prestações que se pode exigir diante de um e de outro. Daí que
a saúde do trabalhador se trata de um direito humano fundamental de natureza
negativa e positiva, exigindo tanto do empregador quando do Estado não somente a
abstenção de práticas que ocasionem enfermidade física ou mental do trabalhador,
mas também uma positividade, ou seja, a adoção de medidas preventivas de doenças
e acidentes. Aí estão os dois aspectos essenciais do referido direito: a) o direito à
abstenção; e b) o direito à prestação, por sua parte subdivido em direito à prevenção
e direito à reparação.

O direito à saúde é considerado tanto um direito de defesa, ou seja, defender e garantir a saúde do trabalhador, impedindo sua não proteção e omissões diretas por parte das empresas, bem como acidentes de trabalho e doenças decorrentes da atividade laborativa, 
sendo também considerado um direito positivo, de prestações e ações de fazer por parte do Estado, no exercício de seu poder de polícia, bem como ao empregador e às empresas, devendo garantir ambientes salubres e seguros de trabalho, sob pena de responsabilização nas esferas administrativa, civil e penal.

A Constituição Federal traz em seu texto diversas passagens que dizem respeito à saúde e segurança do trabalhador, que são constitucionalmente assegurados. Os valores sociais do trabalho e a dignidade da pessoa humana estão dispostos no diploma constitucional no artigo $1^{\circ}$, incisos III e IV, sendo considerados fundamentos da República Federativa do Brasil. $\mathrm{O}$ artigo $6^{\circ}$ dispõe que a saúde é um direito social, e o artigo $7^{\circ}$, inciso XXII disciplina que a redução de riscos inerentes ao trabalho é um direito fundamental, devendo ser estabelecidas normas de saúde, higiene e segurança do trabalho.

Em relação aos direitos sociais e sua efetividade, Silva (1999, p. 289) disciplina que:

\begin{abstract}
Assim, podemos dizer que os direitos sociais, como dimensão dos direitos fundamentais do homem, são prestações positivas proporcionadas pelo Estado direta ou indiretamente, enunciados em normas constitucionais, que possibilitam melhores condições de vida aos mais fracos, direitos que tendem a realizar a igualização de situações sociais desiguais. São, portanto, direitos que se ligam ao direito de igualdade. Valem como pressupostos do gozo dos direitos individuais na medida em que criam condições materiais mais propícias ao aferimento da igualdade real, o que, por sua vez, proporciona condição mais compatível com o exercício efetivo da liberdade.
\end{abstract}

O ordenamento jurídico brasileiro possui todo um arcabouço normativo responsável por garantir uma vida digna à todos, de modo equilibrado e responsável, também no meio ambiente de trabalho e relações de emprego. Não apenas a saúde física do trabalhador é protegida no âmbito legal, como também sua saúde mental, psicológica, espiritual, social, cultural, e todas as vertentes abrangidas pelo campo da saúde.

Ocorre que nem sempre as normas constitucionais são aplicadas e observadas na prática, sendo detectadas inércias estatais nas funções de garantia e efetivação dos direitos previstos legalmente, em especial ao direito social à saúde, inerente à todos os seres humanos, que é um dever do Estado, conforme assegurado no artigo 196 da Constituição Federal, constando expressamente que o Estado deve realizar políticas econômicas e sociais que visem à redução dos riscos de doenças e de outros agravos e ao acesso universal e igualitário às ações e serviços para sua promoção, proteção e recuperação.

Neste sentido, é o entendimento de Ferraz (2015, p. 217): 


\begin{abstract}
A Constituição, obra de um Poder mais alto, solenemente promulgada, destina-se a ser efetivamente observada, cumprida e aplicada (...). E, com efeito, se se aceita a Constituição como obra de compromisso posta pelos constituintes no exercício do Poder Constituinte Originário, que lhes é conferido pelo povo, é de se esperar que a Constituição escrita seja aplicada plenamente, em especial pelos detentores dos poderes constituídos - Legislativo, Executivo e Judiciário - que, em regra, são titulados, pelo Constituinte, guardiães da Constituição.
\end{abstract}

Conforme disciplina o artigo 197 da Constituição Federal de 1988, as ações públicas relativas à políticas e serviços de saúde são dever do Poder Público, que devem dispor sobre sua regulamentação, fiscalização e controle, sendo que a execução dos projetos pode ser feita diretamente pelos órgãos estatais ou através de terceiros, bem como por pessoas físicas ou jurídicas de direito privado.

Embora o Estado careça de recursos financeiros e orçamentários para efetivar direitos positivados à nível constitucional e normativo, é necessário que se busque a máxima garantia e eficácia contida nos direitos à vida, saúde e dignidade humana dos indivíduos pertencentes à sociedade brasileira, devendo o Estado priorizar políticas e verbas para as áreas em questão, tendo em vista sua essencialidade.

O poder estatal possui, portanto, o dever de conferir efetividade aos direitos fundamentais previstos constitucionalmente, sob pena de possuir uma Constituição Federal com letra morta, que não possui mecanismos práticos aptos à assegurarem os direitos nela contidos e estabelecidos, devendo o administrador público atuar de forma vinculada à políticas constitucionais, sendo de responsabilidade do Poder Judiciário controlar eventuais abusos ou omissões em relação à legalidade dos atos produzidos.

\title{
5 IMPACTOS NA SAÚDE DO TRABALHADOR DECORRENTES DAS MODALIDADES DE TRABALHO REMOTAS DO TELETRABALHO E HOME OFFICE
}

A pandemia ocasionada pelo coronavírus causou inúmeras mudanças de pensamento e comportamento na sociedade civil contemporânea, que nunca tinha vivenciado tempos de calamidade sanitária parecidos, sendo as relações interpessoais profundamente impactadas. Houve então a necessidade de haver uma adaptação ao novo normal, com o aprendizado e a utilização de novas tecnologias e mecanismos de alto avanço informático por parte dos 
trabalhadores e seu fornecimento por partes das empresas de pequeno, médio e grande porte empregadoras.

Inúmeros são os impactos causados à saúde do trabalhador tendo em vista as modalidades de trabalho remotas do teletrabalho e home office, apresentando desvantagens para todas as partes envolvidas na relação de trabalho. Em relação ao trabalhador, o principal impacto causado é justamente em sua saúde emocional, mental e social, tendo em vista os danos sofridos causados pelo isolamento social, não possuindo contato com colegas de trabalho e colaboradores, com consequente queda na produtividade e autoestima.

Aqueles trabalhadores que operam em domicílio tendo em vista o período pandêmico que o país e o mundo está passando, encontra dificuldades em adaptar-se à nova rotina de trabalho, bem como conciliá-la com a convivência familiar e os espaços físicos e tecnológicos oferecidos por sua residência, tendo muitas vezes que gerar uma reestruturação nos espaços da casa, adaptando-os para o trabalho remoto.

As empresas e demais empregadores, por sua vez, encontram dificuldades em treinar suas equipes de funcionários à distância, bem como passar adequadamente as instruções e novos comandos, fazendo com que a produção diminua consideravelmente, ao passo que na empresa as dúvidas eram tiradas de modo imediato na forma verbal, presencialmente, com instruções e demonstrações práticas dos procedimentos, bem como com o auxílio de terceiros especializados, o que muitas vezes não é possível imediatamente no regime de trabalho remoto, sendo que as respostas podem ser mais demoradas e obscuras.

Com as modalidades remotas, os trabalhadores ficam mais depressivos e ansiosos, o que foi agravado principalmente nos períodos pandêmicos devido ao isolamento e à crise sanitária vivenciada no país, tendo em vista que os seres humanos são sociais por natureza e necessitam consequentemente de comunicação entre seus pares para o pleno desenvolvimento social e individual, enquanto pessoa singular e membro da coletividade.

O trabalhador encontra-se confuso, em especial no regime de teletrabalho, tendo em vista a ausência de horários previamente estabelecidos, não havendo distinção, muitas vezes, entre sua vida pessoal e profissional, causando-lhe assim intenso desgaste físico e emocional, possuindo uma queda considerável em sua produtividade habitual, ainda que aumente sua jornada de trabalho.

A interação entre os trabalhadores de um mesmo setor, ou sua comunicação com os outros setores da empresa, bem como entre equipes, tiveram que se adaptar com as novas 
formas de comunicação virtual. A real efetividade de tecnologias que controlam remotamente o horário de jornada e a consequente produtividade dos empregados também é questionável, tendo em vista que muitas são as maneiras existentes de fraudá-la.

O trabalhador se vê obrigado a ter que provar a produtividade esperada, ainda que esteja em regime domiciliar, a fim de que os empregadores não tenham a errada impressão que, por estarem em suas casas, estão no ócio ou dedicando-se à outras atividades cotidianas. Com isso, a pressão psicológica aumenta ainda mais, o que pode ocasionar sobrecarga e desgaste dos trabalhadores, que devem fielmente registrar o cumprimento de prazos e metas estabelecidos previamente pelas empresas e empregadores.

Outro impacto analisado em empregados que trabalham remotamente é a tendência de se tornarem verdadeiros "workaholics", considerado aquele trabalhador compulsivo, viciado em trabalho, não possuindo tempo para cuidar de sua vida pessoal, social e familiar, isolandose do resto da sociedade e focando unicamente em sua produção laboral, o que é perigoso em tempos capitalistas em que a sociedade está interligada e os indivíduos dependem mutuamente uns dos outros.

O tempo de repouso é um direito fundamental inerente à todos os trabalhadores, a fim de que possam descansar e reparar-se fisicamente e mentalmente para a próxima jornada de trabalho, bem como gerenciar sua vida privada social, familiar, e atividades de lazer, a fim de que obtenha maior desempenho ao regressar ao trabalho. José Augusto Rodrigues Pinto e Rodolfo Pamplona Filho (2000, p. 452) entendem, nesse sentido, que:

Os repousos do trabalhador formam um sistema de equilíbrio com os períodos de trabalho durante os quais o empregado deve a prestação da energia posta à disposição dos fins da empresa, de modo a utilizá-la em três planos de aproveitamento - orgânico, social e econômico. Por isso, as legislações fundamentadas em estudos de Medicina do Trabalho, estabelecem para eles uma escala de duração em inteira correspondência com a escala de duração do trabalho, resultante da execução continuada, que é um dos caracteres do contrato individual.

O trabalho remoto também pode ocasionar ou impulsionar o desenvolvimento de diversas patologias consideradas psíquicas, como ansiedade, depressão, jornadas exaustivas, assédio psicológico, solidão, tristeza profunda, dentre diversas outras. Como consequência, outras doenças físicas aparecem em decorrência das psíquicas, como dores de cabeça, alteração no sistema imunológico, dores no corpo, cansaço físico, estresse, gastrite, insônia, angústia, variações no humor, inflamações, indisposições, dentre outras. 
Tendo em vista a ausência de descanso, muitas vezes ocasionada pelas exaustivas jornadas de trabalho e falta de sua separação com a vida pessoal e social dos trabalhadores, surge o direito à desconexão, que objetiva limitar a jornada de trabalho dos empregados a fim de que seja respeitado os horários necessários de repouso e recuperação física e psicológica dos mesmos, a fim de assegurar direitos básicos aos trabalhadores como à vida privada, saúde, segurança, lazer, dentre tantos outros.

Acerca do tema direito à desconexão, ressalta Vólia Bomfim Cassar (2014, p. 660):

\footnotetext{
O trabalhador tem direito à desconexão, isto é, a se afastar totalmente do ambiente de trabalho, preservando seus momentos de relaxamento, de lazer, seu ambiente domiciliar, contra as novas técnicas invasivas que penetram na vida íntima do empregado.
}

Ocorre que o trabalho remoto foi a única solução encontrada por muitas empresas para conseguir manter suas atividades, seus postos de trabalho e não terem que demitir funcionários em massa devido ao cenário vivenciado pela pandemia. Com isso, estabeleceram e implantaram políticas internas e normas acerca dos trabalhos remotos, além das já estabelecidas em diplomas legais-normativos brasileiros.

Uma gestão despreparada e inadequada dos trabalhadores que encontram-se em regime de teletrabalho em tempos de pandemia pode ocasionar inúmeros malefícios, que serão somados à toda tensão e diversas outras preocupações existentes no atual cenário, como o receio do avanço do coronavírus tendo em vista o aumento do número de mortes, casos e doentes, medo excessivo e constante, incertezas, dentre outros.

Necessário, portanto, que empresas e empregadores procurem evitar impactos negativos na saúde do trabalhador que encontra-se em regime de trabalho remoto, principalmente em decorrência da pandemia, com treinamentos e suportes de qualidade, equipe técnica preparada para as novas mudanças, bem como apoio emocional e psicológico aos trabalhadores, tudo de forma estruturada e com planejamento e execução adequados, a fim de que todas as partes da relação sofram menos impactos negativos possíveis ocasionados por tantas mudanças repentinas diretas e indiretas na vida de todos.

\section{CONCLUSÃO}


O avanço tecnológico e seu consequente reflexo em todos os setores sociais, como economia, comunicação, trabalho, dentre outros, ocasionou a necessidade de um amparo normativo-legal visando a regulamentação do tema. O teletrabalho, portanto, foi disciplinado através da Lei $\mathrm{n}^{\circ}$ 13.647/17, conhecida como "Reforma Trabalhista", responsável pelo disciplinamento e positivação do instituto.

Com isso, houve o avanço e aumento considerável dos postos de trabalho remotos, sendo que, aos poucos, e de modo crescente, o home office e o teletrabalho foram sendo adotados por grandes e pequenas empresas no cenário nacional e mundial. Ocorre que, no final do ano de 2019, um novo vírus foi descoberto, sendo considerado um dos mais letais e contagiosos existentes até o presente momento.

O coronavírus, como foi chamado, apelidado de "Covid-19", tendo em vista o ano do surgimento da doença, foi identificado pela primeira vez em Wuhan, na China. Os principais sintomas evidenciados pela infecção causada pelo vírus são cansaço, tosse seca e febre. Sintomas secundários são dores de cabeça, de garganta, congestão nasal, perda do olfato ou paladar, dentre outros.

Com a pandemia ocasionada pelo coronavírus, a vida de milhares de pessoas mudaram em torno de todo o globo terrestre, sendo que não foi diferente no Brasil. As mudanças se deram nas mais diferentes áreas humanas e da sociedade, sendo que com as relações trabalhistas e o meio ambiente de trabalho não ocorreu de modo diferente, tendo em vista que para evitar a propagação e contágio do vírus foram necessárias mudanças estruturais e comportamentais na maioria dos setores sociais e trabalhistas existentes.

É preciso que sejam buscadas maneiras de se equilibrar a saúde física e emocional dos trabalhadores em meio à crise sanitária do coronavírus, tendo em vista que os regimes de trabalho remoto não garantem a observância de regras relacionadas à segurança e saúde dos trabalhadores, por diversos motivos, tanto falta ou deficiência na fiscalização pelas empresas e empregadores como por órgãos públicos governamentais, ausência de informação acerca dos direitos assegurados e procedimentos de observância obrigatória, dentre outros.

Os trabalhos exercidos remotamente apresentam tanto aspectos positivos como também inúmeros pontos negativos e desvantagens, que atingem diretamente a saúde dos trabalhadores que exercem suas atividades fora das dependências da empresa, sendo que as maiores desvantagens observadas são o aumento considerável na jornada de trabalho, isolamento, sentimento de solidão, insegurança, queda nos rendimentos e na produtividade, 
falta de suporte e apoio técnico, impossibilidade de faltas por motivo de doença e saúde, elevação de custos, dificuldade para atingimento de metas e progresso nas carreiras, dentre outras.

Portanto, o trabalho remoto foi implementado de forma emergencial por diversas empresas nacionais e multinacionais tendo em vista a pandemia causada pelo coronavírus e a crise sanitária enfrentada. Porém, se o objetivo é implementar o trabalho remoto nos regimes de teletrabalho ou home office, é necessário que a empresa conte com um planejamento e organização a fim de que medidas alternativas existam para que sejam sanadas as dificuldades enfrentadas pelos empregados, bem como suporte de qualidade, logística, e toda uma estrutura pré-estabelecida adequada para tanto, com condições que minimizem os riscos e maximizem a qualidade do trabalho exercido e sua produtividade.

\section{REFERÊNCIAS}

ALMEIDA, Almiro Eduardo de. SEVERO, Valdete Souto. Direito à Desconexão nas Relações Sociais de Trabalho. São Paulo: LTr, 2014.

ANDRADE, Everaldo Gaspar Lopes de. Direito do Trabalho e Pós-modernidade: Fundamentos para uma Teoria Geral. São Paulo: LTr, 2005.

ARAÚJO, Luiz Alberto David; NUNES JÚNIOR, Vidal Serrano. Curso de Direito Constitucional. 4.ed. São Paulo: Saraiva, 2001. 
BARBOSA, Robinson Luís Duarte. O Teletrabalho Dentro de uma Visão mais Ampla da Subordinação Jurídica. Revista Direito e Liberdade. Natal, v. 3, n. 2, p. 607-628, set. 2006. Disponível em:

<https://bdjur.stj.jus.br/jspui/bitstream/2011/60010/teletrabalho_dentro_uma_barbosa.pdf>. Acesso em: 21 mar 2021.

BASTOS, Celso Ribeiro. GANDRA MARTINS, Ives. Comentários à Constituição do Brasil, Promulgada em Cinco de Outubro de 1988. São Paulo: Saraiva, 1988.

BRASIL. Consolidação das Leis do Trabalho. Rio de Janeiro: Presidente da República, 1943. Disponível em: <http://www.planalto.gov.br/ccivil_03/decretolei/del5452.htm>. Acesso em: 29 mar 2021.

BRASIL. Constituição da República Federativa do Brasil. Brasília: Senado Federal, 1988. Disponível em: <http://www.planalto.gov.br/ccivil_03/Constituicao/Constituicao.htm>. Acesso em: 20 mar 2021.

CASSAR, Vólia Bomfim. Direito do Trabalho. 9.ed. São Paulo: Método, 2014.

FERRAZ, Anna Candida da Cunha. Processos Informais de Mudança da Constituição. 2ed. Osasco: EdiFIEO, 2015.

GRASSELI, Odete. O Direito Derivado da Tecnologia: Circunstâncias Coletivas e Individuais no Direito do Trabalho. São Paulo: LTr, 2010.

JURISPRUDÊNCIA DO TST SOBRE TELETRABALHO. Portal TRT 3 Jus, 2016. Disponível em: <https://portal.trt3.jus.br/internet/conheca-o-trt/comunicacao/noticiasjuridicas/importadas-2015-2016/jurisprudencia-do-tst-sobre-teletrabalho-06-03-2016-21-23acs>. Acesso em: 29 mar 2021.

MARTINEZ, Luciano; POSSÍDIO, Cynthia. O Trabalho nos Tempos do Coronavírus. São Paulo: Saraiva, 2020.

MENDES, Gilmar Ferreira; COELHO, Inocêncio Martins; GONET, Paulo Gustavo.

Hermenêutica Constitucional e Direitos Fundamentais. Brasília: Brasília Jurídico, 2000.

RODRIGUES PINTO, José Augusto. PAMPLONA FILHO, Rodolfo. Repertório de Conceitos Trabalhistas. v. I. Direito Individual. São Paulo: LTr, 2000.

SILVA, Homero Batista Mateus da. Comentários à Reforma Trabalhista. São Paulo: Ed. Revista dos Tribunais, 2017.

SILVA, José Afonso da. Curso de Direito Constitucional Positivo. 16. ed. São Paulo: Malheiros, 1999. 
SILVA, José Antônio Ribeiro de Oliveira. Flexibilização da Jornada de Trabalho e a Violação do Direito à Saúde do Trabalhador: uma Análise Comparativa dos Sistemas Jurídicos Brasileiro e Espanhol. São Paulo: LTr, 2013. 